\title{
André Lhote e a obra "Interior com figuras femininas" (1936) do acervo do MASP
}

\author{
Bárbara Diniz Gonçalves ${ }^{1}$ \\ DOI 10.20396/eha.vil4.3367
}

André Lhote, nascido em Bordeaux no ano de 1885, foi escultor, pintor, crítico e educador. Ele atuou nos círculos de arte franceses desde meados da década de 1910, inicialmente em sua cidade natal e, poucos anos depois, em Paris. Preocupado com a prática e com as teorias da pintura, ele realizou ampla produção pictórica e escrita, essa última compreendendo textos críticos, livros e artigos sobre aspectos da produção das vanguardas e tratados sobre paisagem e figura. De reputação considerada independente, o artista-escritor pôde transitar por diferentes movimentos e debates artísticos, com destaque ao Cubismo e suas variadas referências. Telas representativas de diferentes momentos de sua carreira como pintor fazem parte dos acervos de museus paulistas, entre elas "Interior com figuras femininas"2, pintada por ele quase três décadas após o início de suas atividades nas artes plásticas e que, de fato, conjuga em si múltiplas e distintas referências.

A proposta da pesquisa disse respeito, portanto, ao estudo da supracitada pintura no que concerne a seus aspectos temático, pictórico, contextual e mercadológico. A análise do quadro e de sua trajetória enquanto objeto artístico, bem como dos trânsitos realizados pelo próprio artistaescritor, teve como baliza temporal os anos de 1919 a 1947: do início das publicações de textos críticos de Lhote na Nouvelle Revue Française 3 à entrada de "Interior com figuras femininas" para a coleção do MASP. A pesquisa abrangeu o ambiente cultural em que o quadro foi produzido, os elementos pictóricos nele presentes, os diálogos que ele estabelece com a teoria artística de Lhote e seu percurso como objeto inserido no mercado de arte da década de 1940. O artista-escritor revelou-se caso paradigmático para se analisar os conceitos artísticos em disputa no seu período ${ }^{4} \mathrm{e}$

\footnotetext{
1 Bacharela e licenciada em História. Esta publicação faz parte da pesquisa de Iniciação Científica e de monografia de bacharelado de mesmo título, orientada pelo Prof. Dr. Gabriel Ferreira Zacarias e desenvolvida no Departamento de História da Universidade Estadual de Campinas. A pesquisa contou com financiamento do Fundo de Apoio ao Ensino, Pesquisa e Extensão (FAEPEX - UNICAMP). Termo de concessão da bolsa: 2557/18.

2 André Lhote, Interior com figuras femininas, 1936. Óleo sobre tela, 117 x $89.5 \mathrm{~cm}$. Museu de Arte de São Paulo Assis Chateaubriand (MASP). Disponível em:<https://masp.org.br/acervo/obra/interior-com-figuras-femininas>. Acesso em 19 de Dezembro de 2019.

3 Lhote manteve o cargo como redator do periódico durante 23 anos. Os 273 artigos de sua autoria publicados durante esse período podem ser vistos no site <http://www.lanrf.fr/> consultado em 17 de Setembro de 2018.

4 Contextualmente, ressaltamos o surgimento de estéticas consideradas de vanguarda, as novas funções dos escritos de artistas e debates sobre gêneros pictóricos, além, é claro, da pesada e violenta marca exercida pela Primeira Guerra Mundial no campo social, econômico e artístico francês.
} 
a posterior construção das narrativas canônicas da Arte Moderna; a pesquisa documental, por sua vez, possibilitou a descoberta do trajeto da obra até São Paulo.

Inicialmente, constatamos que as variadas atividades de Lhote condicionaram interpretações igualmente múltiplas sobre seus espaços na história da pintura moderna. Durante a pesquisa, optou-se por tomar a produção pictórica, a escrita teórica e as aulas que o artista proferiu como objetos inter-relacionados. O estudo conjunto dos produtos de tais atividades permite, portanto, leituras amplas acerca do referido trânsito de Lhote por estilos e referências diversas, as quais são uma forma de acesso relevante aos debates e conceitos artísticos do início do século XX que possuem mais matizes do que categorizações de escolas artísticas são capazes de abarcar. Reiteramos, enfim que a abordagem passou - e passa - pela noção de que a atuação de Lhote ocorreu em atividades distintas, com estruturas distintas e que produziram trabalhos fruídos também de modo distinto. A leitura de uma não é condicionada à de outra, portanto; buscamos, sim, identificar seus pontos de contato, diferenças e complementaridades.

A justificativa da pesquisa se assentou na curiosa escassez de trabalhos em língua portuguesa sobre o artista e a pintura, visto que Lhote foi professor de pintores brasileiros de renome - Tarsila do Amaral, por exemplo-, seus livros fizeram parte da biblioteca de artistas e intelectuais como Alexandre Eulálio e Renina Katz e uma filial de sua Academia de Arte funcionou, na década de 1950, no Rio de Janeiro. Destaca-se ainda, nesse sentido, a proposta de enriquecer os estudos sobre acervos tão importantes de museus paulistas, sendo que a coleção e o espaço expositivo do MASP, especificamente, têm sido focos de pesquisas de universidades de São Paulo nos últimos anos 5 .

Em termos de método, colocou-se em prática a dialética entre o objeto - nesse caso, a obra pictórica - e a construção do método de investigação. Buscou-se responder de que forma se deram os deslocamentos materiais e simbólicos no contexto das vanguardas artísticas francesas, a partir de um quadro que mobiliza inúmeros conceitos da História da Arte e de uma figura que exerceu muitas atividades nesse âmbito e que não entrou para as narrativas canônicas sobre os movimentos. A elaboração do trabalho passou pelo questionamento da possibilidade de uma única metodologia ou de uma teoria que se aplica, e pela concepção de que cada problema, na História da Arte, demanda um conjunto de estratégias distinto. Nesse sentido, Linda Nochlin mobiliza o conceito de bricolagem: "construir o método conforme se segue para atender às necessidades do material

5 Um número expressivo de trabalhos sobre o acervo do MASP com foco em conteúdos diversos tem sido realizado no Instituto de Filosofia e Ciências Humanas da Universidade Estadual de Campinas. e no âmbito do Programa de Pós-Graduação Interunidades em Estética e História da Arte da Universidade de São Paulo. 
e do desenvolvimento da argumentação e examinar o material, por sua vez, à luz do argumento construído"6.

Dessa forma, a divisão de conteúdo feita nas três partes da monografia, que foi apresentada como resultado final da pesquisa, objetivou evidenciar as soluções encontradas para suprir as necessidades do objeto e para construir as interpretações historiográficas em torno dele. A primeira parte, "Avant-Garde, Cubismo e crítica de arte: a obra de André Lhote", inicia-se com uma breve biografia de Lhote e segue apresentando a situação temporal de sua obra desde 1919, quando publicou o artigo De la nécessité de théories, até 1936, data da pintura do quadro e de seu envolvimento com os debates que diziam respeito à Querela do Realismo. A ela, segue-se "A aquisição de Interior com figuras femininas pelo MASP", cujo argumento passa pela história institucional do Museu de Arte de São Paulo Assis Chateaubriand em relação com as políticas culturais paulistas, pelas mudanças de concepção museológica emergentes no mundo ocidental no pós Segunda Guerra Mundial e pela facilidade prática de aquisição de obras provenientes de uma Europa em crise econômica. Finalmente, no capítulo que encerra o trabalho, "A análise pictórica: uma narrativa da História da Arte", os signos da pintura foram colocados em diálogo com suas referências textuais e pictóricas.

Como se disse, as produções escrita, pictórica e pedagógica de Lhote estão intrinsecamente ligadas - daí, inclusive, a escolha metodológica de chamar Lhote "artista-escritor". Não foi o objetivo da pesquisa, no entanto, aprofundar o estudo sobre essas produções escritas; selecionamos textos de sua autoria para a construção do argumento, com destaque aos artigos publicados em Les invariants plastiques - uma compilação que traz oito de seus textos de 1919 a 1948, originalmente publicados na imprensa. Essa análise se mostrou uma forma de acesso importante para os conceitos mobilizados pelo artista-escritor sobre sua própria obra e sobre suas leituras acerca das artes de seu período. A partir do entendimento desses conceitos, pôde-se identificar as concordâncias, discordâncias e complementaridades entre as interpretações elaboradas pelo artista e a sua pintura, objeto da pesquisa. Com o objetivo de evidenciar o que essa abordagem gerou em termos de resultados, um excerto desse tipo de análise será, então, aqui apresentado.

Um dos argumentos defendidos por André Lhote em Les invariants plastiques, é que a forma é o suporte indestrutível de uma cor perecível. Este argumento diz respeito ao sistema de regras de acordo com o qual haveria conjugação da forma, arquitetura preliminar da pintura, com a cor, que

\footnotetext{
6 No original: "constructing your method as you go along to suit the needs of the material and the evolving argument and, in turn, examining the material in the light of the argument so constructed". In: NOCHLIN, Linda. Representing Women. London: Thames \& Hudson, 1999. p. 10.
} 
seria perecível na ausência da estrutura do desenho. Ao tratar das “invariantes plásticas”, portanto, ele está se referindo a essas formas elementares que estariam presentes em todo e qualquer trabalho plástico. No artigo A la recherche des invariants plastiques, de 1948, ele define as três principais: "o desenho, ou sinal expressivo, que existiu antes de qualquer cor ou modelo; a cor, ou oposição de tons quentes e frios; la valeur, ou a oposição de tons claros e escuros"7.

Essa ideia pode ser posta em diálogo, justamente, com "Interior com figuras femininas". Nele, uma profusão de ângulos retos limita as áreas de cor e estrutura geometricamente as cinco figuras femininas. Essas áreas se localizam, principalmente, no interior da delimitação criada pelo arco, mas exercem influência também na disposição e no uso de cores da figura feminina maior, em primeiro plano. Tal arco, ao mesmo tempo em que se constitui como um edifício e um suporte físico, abre um outro plano dentro da tela, no qual as três figuras são diminutas. Embora ele seja a porta de entrada para uma arquitetura, ou um espaço interior, o jogo abstrato-geométrico sugere um universo muito pouco concreto em relação à materialidade e disposição do espaço perspectivo. $\mathrm{O}$ arco sedimenta essa divisão de planos e, assim como as personagens situadas nos primeiros planos, tem um peso estrutural.

Do lado esquerdo do observador, tomando como parâmetro o centro situado a nível da linha superior das impostas, precisamente no meio da estrutura, o arco é simulado de um ponto de vista diagonal. O tom de azul é claro e as nuances alaranjadas dão à superfície um efeito de iluminação. A combinação das cores azul e verde, bem como o laranja vivo de sua parte interna, cumprem o mesmo papel de gerar uma impressão de claridade. Do lado direito, a tonalidade de azul é a mais fechada de toda a composição. Ainda assim, apresenta nuances claras, que resistem à planaridade de cor. Nele, por sua vez, simula-se, uma perspectiva frontal. Essas características são exemplares dos posicionamentos híbridos de Lhote em relação às referências que ele seleciona na História da Arte. Aqui, um objeto de diretrizes clássicas é representado segundo a proposta cubista do início do século de simultaneidade de pontos de vista distintos.

Sobre as figuras femininas em si, enfocaremos as de primeiro e segundo plano. A do segundo plano, em pé, marcada por poses rígidas e traços faciais simplificados, evidencia conceitos escultóricos. Tais conceitos remetem à série de pinturas de base escultórica realizadas por Picasso entre

\footnotetext{
7 No original: "En attendant de noter au passage, dans des chefs d'oeuvre indiscutés, ces éléments du tableau, énumérons les principaux: 1. le dessin, ou signe expressif, ou ornement qui pré-existe à toute couleur et à tout modelé;

2. la couleur, ou opposition de tons chauds et froids;

3. la valeur, ou opposition des tons sombres et clairs." In: LHOTE, André. "A la recherche des invariants plastiques (1948)". In: plastiques. Paris: Hermann, 1967. p. 89. 
1905 e 1906 e que dialogam com esculturas e alto-relevos em calcário produzidos em torno do ano 100 a.C. no Sul e no Sudeste da Península Ibérica. Uma série desses objetos foi exposta no Musée du Louvre na época, e há registros de que Picasso visitou a mostra ${ }^{8}$. Como pode ser percebido no esboço de Picasso intitulado "Toalete (Fernande)" há a proeminência de uma paleta de cores terrosas e de uma pose rígida. A bidimensionalidade da construção da figura desafia os tradicionais recursos ilusionistas ao mesmo tempo em que denota um retorno aos modelos mediterrâneos. Esses dois aspectos - a figura escultórica e o arco pleno parecem fazer ainda referência à Pierre Puvis de Chavannes: a localização geográfica genérica, as colunas clássicas, os tons suaves, as figuras femininas rígidas, idealizadas, descobertas ${ }^{10}$.

Quanto à temática com a qual dialoga a figura em primeiro plano, destaca-se o tópico orientalista também mobilizado, por exemplo, por Delacroix e por Matisse. Embora outros pintores de diferentes localidades e momentos históricos tenham trabalhado com o tema, ambos foram escoIhidos para efeitos de análise por terem sido especificamente referenciados por Lhote em diferentes textos escritos.

Em termos de postura corporal, essa figura remete a características das duas concubinas posicionadas na esquerda e na direita da obra "Femmes d'Alger dans leur appartement"11, de Delacroix, sendo um amálgama destas. É sobretudo no posicionamento das pernas e dos braços que se faz a referência. O braço que se apóia na almofada não deixa dúvidas: ele se mostra, em ambas as mulheres pintadas, tensionado e ao mesmo tempo suave, terminando em uma mão solta de maneira graciosa e despretensiosa. Essa almofada é, em si, uma citação. Trazendo também coloridas padronagens decorativas, a que existe na obra de Lhote harmoniza com as cores e formas ornamentais do tecido com o qual a figura ao lado se cobre e com o aspecto decorativo do quadro como um todo.

Alguns dos mesmos elementos do suposto oriental, aqui analisados em Delacroix e que tam-

\footnotetext{
8 Segundo o curador norte-americano James Sweeney, “(...) foi na primavera de 1906 que a arte ibérica recebeu sua maior publicidade em Paris graças à instalação das esculturas de Osuna no Louvre. A visita de Picasso à Espanha no verão de 1906 provavelmente deu um calor adicional a esse entusiasmo pela arte ibérica. E, em seu retorno a Paris, essa nova influência teve, sem dúvida, mais liberdade para se inserir em sua própria expressão (...)". No original: "(...) it was in the spring of 1906 that Iberian art had received its widest publicity in Paris thanks to the installation of the Osuna sculptures in the Louvre. Picasso's visit to Spain in the summer of 1906 probably gave an added warmth to this enthusiasm for Iberian art. And on his return to Paris this new influence was undoubtedly more at liberty to work its way into his own expression (...)" In: SWEENEY, James Johnson. Picasso and iberian sculpture. The Art Bulletin, v. 23, n. 3, p. 191-198, 1941. p. 193.

9 Pablo Picasso, Toalete (Fernande), 1906. Óleo sobre tela sobre papelão, $53 \times 31 \times 1.7 \mathrm{~cm}$. Museu de Arte de São Paulo Assis Chateaubriand (MASP). Disponível em: <https://masp.org.br/acervo/obra/toalete-fernande>. Acesso em 04 de Junho de 2019.

10 Ver, por exemplo, Pierre Puvis de Chavannes, Le Bois sacrécher aux arts et aux muses, 1884 . Óleo sobre tela, $460 \times 1040 \mathrm{~cm}$. Musée des beauxarts de Lyon. Disponivel em: <http://www.mba-lyon.fr/mba/sections/fr/collections-musee/peintures/oeuvres-peintures/xixe_siecle/le_bois_ sacre_cher_a/>. Acesso em 04 de Junho de 2019.

11 DELACROIX, Eugène. Femmes d'Alger dans leur appartement, 1834. Óleo sobre tela, 180 x 229 cm, Musée du Louvre. Disponível em: <https:// www.louvre.fr/oeuvre-notices/femmes-dalger-dans-leur-appartement>. Acesso em 06 de Junho de 2019.
} 
bém aparecem em Lhote, constam nesta cena de "Seated Odalisque, Left Knee Bent, Ornamental and Checkered Background", de Matisse ${ }^{12}$ : tapetes, roupas, alimentos em louças que são apoiadas no chão e papéis de parede de variadas padronagens ornamentais. As vestimentas da odalisca de Matisse, ainda que sejam mais adornadas, assemelham-se muito às da figura de Lhote. As calças de ambas as figuras são largas e avultadas; ao mesmo tempo em que elas cobrem seus corpos, o aspecto de tais dobras e a posição das pernas, cruzadas ou dobradas para cima, direcionam a visão do observador para suas vaginas. É essa a demonstração mais sutil da hegemonia do olhar masculino e branco, para o qual são feitas e se dirigem as representações de mulheres e, nesse caso, de mulheres não-ocidentais. Para apoiar essa análise, nos voltamos principalmente a Edward Said e a Linda Nochlin. Segundo Said,

No sistema de conhecimento sobre o Oriente, este é menos um lugar que um topos, um conjunto de referências, uma coleção de características, que parece ter a sua origem em uma citação, ou em um fragmento de um texto, ou em uma referência à obra de alguém sobre o Oriente, ou em um extrato de imaginação anterior, ou em um amálgama de tudo isso. A observação direta ou a descrição circunstancial são as ficções apresentadas pelos escritos sobre o Oriente, mas estes, invariavelmente, são totalmente secundários em relação a trabalhos sistemáticos de outra espécie. ${ }^{13}$

E, ainda, de acordo com Nochlin"14, "O homem branco, o ocidental, está, é claro, sempre implicitamente presente em pinturas orientalistas (...); é necessariamente dele o olhar controlador, o olhar que traz o mundo oriental à existência, o olhar para o qual, em última instância, ele se destina." ${ }^{15}$

De volta ao Brasil sintetizaremos agora alguns resultados da pesquisa documental que permitiu traçar a trajetória de Interior com figuras femininas como objeto inserido no mercado de arte e cuja história material está entrelaçada a aspectos da história europeia e brasileira, sobretudo da década de 1940. Com o objetivo de desvendar a procedência do quadro, partiu-se da informação de que a pintura pertenceu à primeira coleção a ser adquirida para o acervo do MASP no ano de 1946.

Assis Chateaubriand, fundador do MASP e dono de uma enorme rede de comunicações, os

\footnotetext{
12 MATISSE, Henri. Seated Odalisque, Left Knee Bent, Ornamental and Checkered Background, 1928. Óleo sobre tela, $54.9 \times 37.8 \mathrm{~cm}$. Baltimore Museum of Art. Disponível em: <http://collection.artbma.org/emuseum/view/objects/asitem/search\$0040/o?t:state:flow=52f82a13-1a59-4f3d93ae-b2857eb7719d>. Acesso em 07 de Junho de 2019.

13 SAID, Edward. Orientalismo — o Oriente como invenção do Ocidente. São Paulo: Companhia das Letras, 1978. p. 185.

14 O artigo de Nochlin foi escrito e publicado no contexto da exposição "Orientalism: The Near East in French Painting 1800-1880". Segundo a própria autora, foi ela que suscitou a reflexão acerca de questões políticas relacionadas às relações entre realismo e poder, violência e o pitoresco, para além das usuais discussões da História da Arte.

15 No original: "The white man, the westerner, is of course always implicitly present in Orientalist paintings (...); his is necessarily the controlling gaze, the gaze which brings the Oriental world into being, the gaze for which it is ultimately intended". In: NOCHLIN, Linda. The imaginary orient. Art in America, v. 71, n. 5, p. 118-131, 1983. p. 121.
} 
Diários Associados, tinha como um dos canais para negociação do acervo, nesse caso com a comunidade artística parisiense, o casal José Maria dos Reis Júnior, brasileiro, e Beatrix Reynal, uruguaia de família francesa. Embora na ficha de catalogação de "Interior com figuras femininas" originalmente constem como doadores os Diários Associados e como procedência o próprio Chateaubriand, o nome Beatrix aparece grafado no verso do chassi da obra. Dada a história de vida do casal e os círculos sociais que eles frequentavam no Brasil e na Europa, era grande a possibilidade de que o quadro de Lhote tivesse de fato feito parte de sua coleção antes de entrar para o acervo do MASP.

A proveniência é confirmada por notícia d’O Jornal, órgão dos Diários Associados, de 2 de Junho de 1946. Ilustrada com reproduções de oito obras, incluindo Interior com figuras femininas, a notícia afirma também que as doze primeiras telas que integraram o acervo do Museu são uma "magnífica coleção de mestres modernos franceses reunida em longos anos de pacientes esforços pela poetisa Beatrix Reynal"16. Os pintores são, então, enumerados:

Doze são os quadros adquiridos dessa coleção primorosa, reunindo os nomes afamados de Claude Monet, Henri Martin, Suzanne Valadon, Maurice Utrillo, Vlaminck, André Lhote, Marie Laurencin, Henry de Waroquier, Albert Marquet, Marc Chagall, Harpignies e Renefer (grifos meus). ${ }^{17}$

Com a análise de uma seleção de periódicos cariocas e paulistas, concluímos, ainda, que a obra foi adquirida durante a missão jornalística que a levou à Europa em 1939, que aconteceu justamente por envio dos Diários Associados, dos quais ela era colaboradora ${ }^{18}$. Isso porque a biografia de Raynal não indica que ela teria voltado à Europa depois da guerra. A descrição da casa em que ela e o marido viviam no Rio de Janeiro, feita pelo jornalista Ubiratan Machado, é relevante também por revelar a presença de obras de Lhote na coleção:

Seu salão - se podemos empregar esse termo, que cheira demais ao século XIX, - na Avenida Vieira Souto, perto do Jardim de Alá, concorria com o de Aníbal Machado, na Visconde de Pirajá. Ambos recebiam Álvaro Moreyra e sua mulher Eugênia, Goeldi, Lúcio Cardoso, Augusto Frederico Schmidt, Rachel de Queiroz, Villa-Lobos, Murilo Mendes e muitos outros. Era uma bela casa, repleta de obras de arte, quadros de Lhotte, Gromaire, Vuillard, e uma imensa biblioteca no segundo andar, segundo depoimento de José Ceraldo Vieira (...). ${ }^{19}$

\footnotetext{
16 MUSEU moderno de arte para o Brasil. O Jornal - Órgão dos Diários Associados, Rio de Janeiro, XXVIII, n. 8.003, 2 jun. $1946.2^{a}$ seção, p. 1.

17 Id. Ibid.

18 CRUZ Vermelha vai reconhecer o mérito de Béatrix Reynal. Correio da Manhã, Rio de Janeiro, $\mathrm{n}^{\circ}$ 22.145 - ano LXV, 16 jun. $1965.1^{\circ}$ caderno, p. 5 19 MACHADO, Ubiratan. A literatura francesa no Brasil durante a II Guerra Mundial. Rio de Janeiro: Revista Brasileira. Fase VII, abr., mai., jun. 2005, ano XI, nº 43. p. 252. Disponível em: <http://www.academia.org.br/abl/media/prosa43d.pdf>. Acesso em 03 de Maio de 2019.
} 
Neste trabalho, por fim, a análise de "Interior com figuras femininas" procurou abranger a maior parte das questões por ele suscitado: o ambiente cultural em que foi produzido, os elementos pictóricos nele presentes, os diálogos que estabelece com a teoria artística do próprio Lhote e seu percurso como objeto inserido no mercado de arte, tendo sido concebido na Paris dos anos de 1930 e exposto em museu paulista a partir da segunda metade da década de 1940. Todas essas questões desembocaram, por fim, na análise da obra em si, de seus elementos formais, citações e referências artísticas. Tal esforço analítico não teria sido possível fora do percurso prescrito pelo estudo sobre Lhote e sobre o MASP, ao mesmo tempo em que os aspectos trabalhados neles não teriam sido selecionados senão a partir das características elucidadas pela própria pintura. Esse procedimento, bem como a própria divulgação dos resultados da pesquisa, enfim, buscam uma compreensão mais ampla das pinturas e de seus agentes em seu próprio tempo do que as narrativas canônicas são capazes de abarcar. 


\section{Referências Bibliográficas}

BOUILLER, Jean-Roch. Art Criticism and Avant-Garde: Andre Lhote's Written Works. Avant Garde Critical Studies, v. 21, pp. 15-31, 2007.

COTTINGTON, David. Cubism in the shadow of war: the avant-garde and politics in Paris 1905-1914. New Haven; London: Yale University Press, 1998.

CRUZ Vermelha vai reconhecer o mérito de Béatrix Reynal. Correio da Manhãa, Rio de Janeiro, $n^{\circ} 22.145$ - ano LXV, 16jun. 1965.

COLDING, John. Cubism: a history and an analysis, 1907-1914. Cambridge: Belknap, 1988.

GREEN, Christopher. Art in France, 1900-1940. London: Yale University Press, 2003.

Cubism and its enemies: modern movements and reaction in French art, 1916-1928. New Heaven; London: Yale University Press, 1978, c1977.

LHOTE, André. Les invariants plastiques. Paris: Hermann, 1967.

MACHADO, Ubiratan. A literatura francesa no Brasil durante a II Guerra Mundial. Rio de Janeiro: Revista Brasileira. Fase VII, abr., mai., jun. 2005, ano XI, nº 43.

MUSEU moderno de arte para o Brasil. O Jornal, Rio de Janeiro, XXVIII, n. 8.003, 2 jun. 1946.

NOCHLIN, Linda. Representing Women. London: Thames \& Hudson, 1999.

The imaginary orient. Art in America, v. 71, n. 5, p. 118-131, 1983.

ROSENBLUM, Robert. Cubism and twentieth-century art. New York: Abrams, 1982.

RUBINO, Silvana. Rotas da modernidade: trajetória, campo e história na atuação de Lina Bo Bardi, 1947-1968. 2002. 256p. Tese (doutorado) - Universidade Estadual de Campinas, Instituto de Filosofia e Ciências Humanas, Campinas, SP. Disponível em: <http://www.repositorio.unicamp.br/handle/REPOSIP/280169>. Acesso em: 25 out. 2018.

SAID, Edward. Orientalismo — o Oriente como invenção do Ocidente. São Paulo: Companhia das Letras, 1978.

SWEENEY, James Johnson. Picasso and iberian sculpture. The Art Bulletin, v. 23, n. 3, p. 191-198, 1941. 